\title{
Effect of Angiotensin II on Bone Erosion and Systemic Bone Loss in Mice with Tumor Necrosis Factor-Mediated Arthritis
}

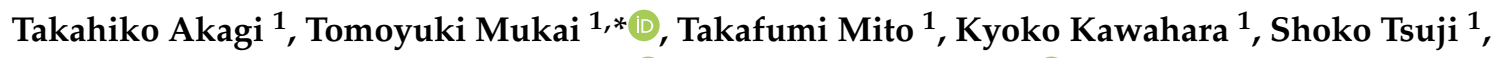 \\ Shunichi Fujita ${ }^{1}$, Haruhito A. Uchida ${ }^{2}{ }^{\mathbb{D}}$ and Yoshitaka Morita ${ }^{1}$ (I) \\ 1 Department of Rheumatology, Kawasaki Medical School, Kurashiki, Okayama 701-0192, Japan; \\ akagitahiko@gmail.com (T.A.); mito.tac@gmail.com (T.M.); kyoko.k0925@gmail.com (K.K.); \\ shoko7.05.13@gmail.com (S.T.); shunic117@gmail.com (S.F.); morita@med.kawasaki-m.ac.jp (Y.M.) \\ 2 Department of Chronic Kidney Disease and Cardiovascular Disease, Okayama University Graduate School \\ of Medicine, Dentistry and Pharmaceutical Sciences, Okayama 700-0914, Japan; hauchida@okayama-u.ac.jp \\ * Correspondence: mukait@med.kawasaki-m.ac.jp; Tel.: +81-86-462-1111
}

Received: 24 April 2020; Accepted: 7 June 2020; Published: 10 June 2020

check for updates

\begin{abstract}
Angiotensin II (Ang II) is the main effector peptide of the renin-angiotensin system (RAS), which regulates the cardiovascular system. The RAS is reportedly also involved in bone metabolism. The upregulation of RAS components has been shown in arthritic synovial tissues, suggesting the potential involvement of Ang II in arthritis. Accordingly, in the present study, we investigated the role of Ang II in bone erosion and systemic bone loss in arthritis. Ang II was infused by osmotic pumps in tumor necrosis factor-transgenic (TNFtg) mice. Ang II infusion did not significantly affect the severity of clinical and histological inflammation, whereas bone erosion in the inflamed joints was significantly augmented. Ang II administration did not affect the bone mass of the tibia or vertebra. To suppress endogenous Ang II, Ang II type 1 receptor (AT1R)-deficient mice were crossed with TNFtg mice. Genetic deletion of AT1R did not significantly affect inflammation, bone erosion, or systemic bone loss. These results suggest that excessive systemic activation of the RAS can be a risk factor for progressive joint destruction. Our findings indicate an important implication for the pathogenesis of inflammatory bone destruction and for the clinical use of RAS inhibitors in patients with rheumatoid arthritis.
\end{abstract}

Keywords: angiotensin II; arthritis; bone erosion; inflammation; tumor necrosis factor; renin-angiotensin system; angiotensin II type 1 receptor

\section{Introduction}

Rheumatoid arthritis is a chronic inflammatory disorder that can cause painful swelling and bone erosion in the inflamed joints [1]. The accumulation of joint damage results in long-lasting pain and deformity of the affected joints [2]. Persistent systemic inflammation in rheumatoid arthritis can also cause tissue damage in organs such as the lungs, heart, eyes, and bone [3]. Increased inflammatory cytokines affect bone metabolism throughout the body and decrease bone mass and strength, leading to increased risks of osteoporosis and fracture [4]. Joint deformities impair activities of daily life and thus exacerbate osteoporosis in patients with rheumatoid arthritis. This highlights the importance of resolving joint damage and systemic bone loss issues in these patients. 
Angiotensin II (Ang II) is the main effector peptide of the renin-angiotensin system (RAS), which causes vasoconstriction and an increase in blood pressure [5,6]. The RAS is one of the most important systems in cardiovascular control [5]. Ang II is generated from its precursor angiotensinogen through serial enzymatic processes mediated by renin and angiotensin-converting enzyme (ACE). Ang II is converted mainly in the kidneys and lungs. Recent studies have shown that Ang II is generated locally in various tissues such as the brain, vascular wall, and reproductive tract $[5,7]$. Locally produced Ang II plays a role in many physiological and pathological processes such as hypertension, inflammation, tissue fibrosis, and oxidative stress [8], and it fulfills a key function in bone metabolism [6,9]. Animal studies have revealed that Ang II and Ang II type1 receptor (AT1R) are expressed locally within bone tissue and regulate bone mass $[6,9,10]$. Additionally, studies using mouse models have indicated that the local RAS is involved in the pathogenesis of several bone diseases, such as postmenopausal [11], age-related [12], and glucocorticoid-induced osteoporosis [13].

Components of the RAS are expressed at elevated levels in the synovium of patients with rheumatoid arthritis compared to those in the non-inflamed synovium $[9,14,15]$. However, the role of the RAS in the mechanisms underlying bone erosion and inflammation-mediated bone loss in arthritic conditions remains unclear. In the present study, we investigated the in vivo effects of Ang II on bone erosion and systemic bone loss in a tumor necrosis factor (TNF)-induced arthritis model. We also aimed to assess whether the deletion of AT1R ameliorates the bone erosion and systemic bone loss caused by arthritis.

\section{Results}

\subsection{Increased AT1R Expression in the Joint Tissue of Tumor Necrosis Factor-Transgenic (TNFtg) Mice}

As a first step to explore the effect of Ang II on arthritis, the expression of Agtr1a, encoding AT1R, in the joints was assessed by quantitative polymerase chain reaction (qPCR). Agtr1a mRNA was detected in the joint tissues from both wild-type (WT) and TNFtg mice, and the expression levels were 2.5-fold elevated in the tissues of the TNFtg mice compared with those in the WT mice (Figure 1A). Increased AT1R protein expression was also shown in arthritic joint tissues by Western blotting (Figure A1A). Immunohistochemical stain of the arthritic joints revealed AT1R expression in the tissues, including proliferated synovial cells (Figure A2B). 
A

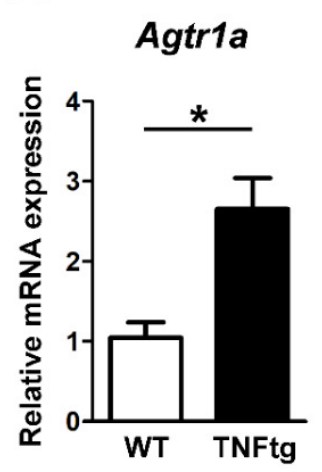

B



C

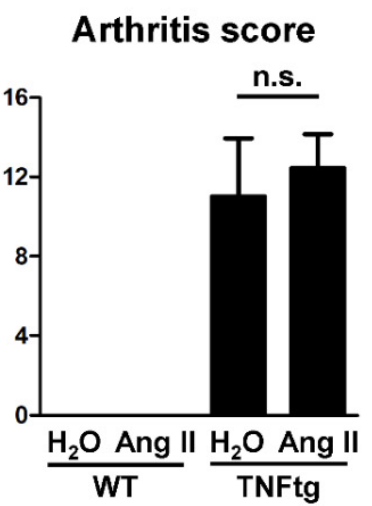

D

Number of arthritic paws

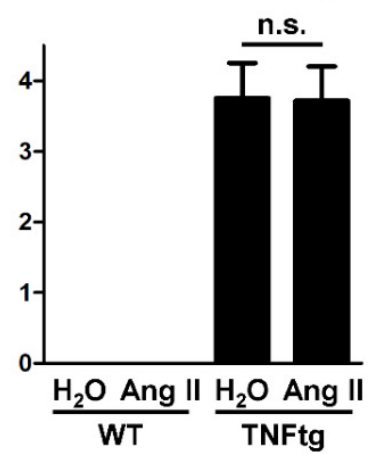

E

WT

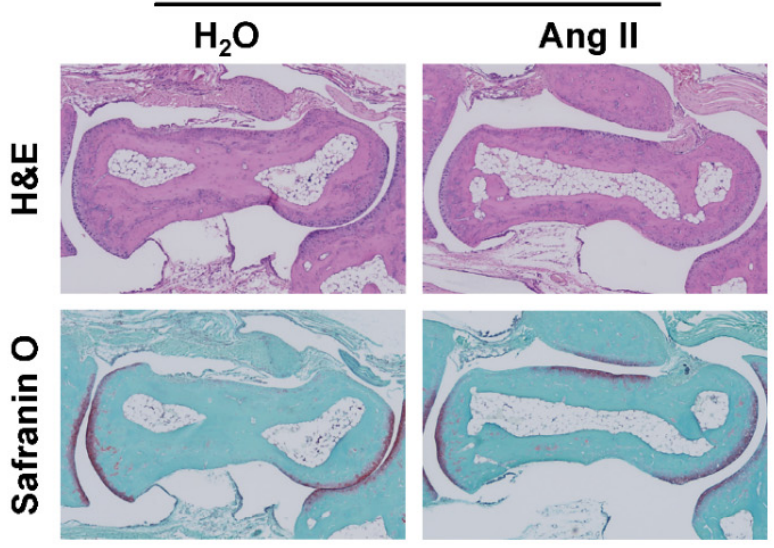

F

Inflammation

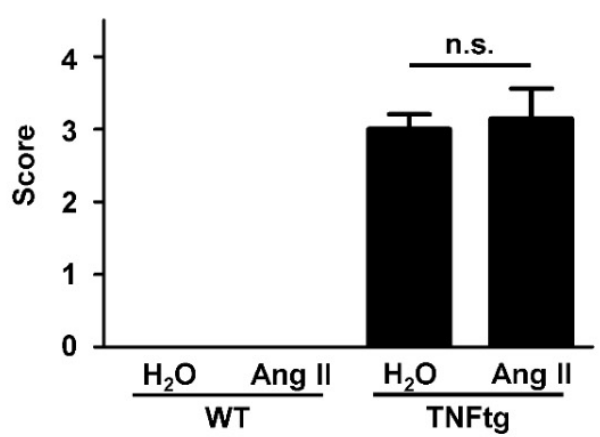

TNFtg

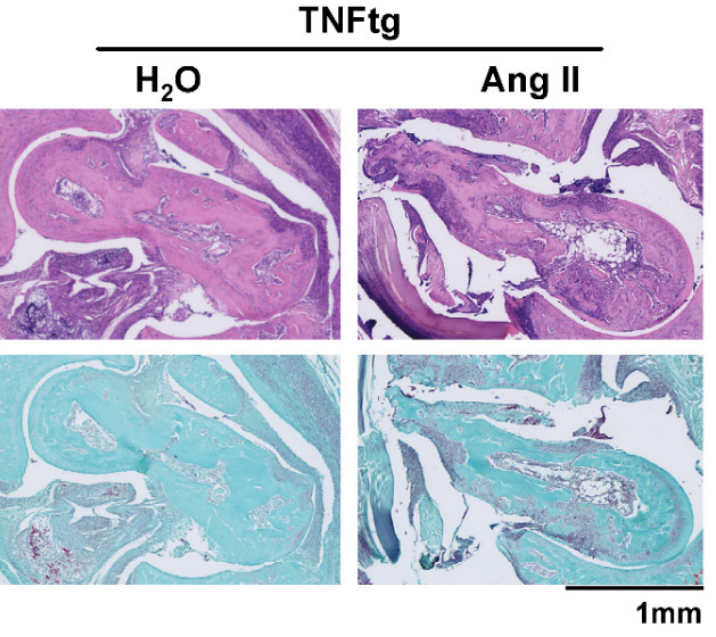

G Cartilage damage

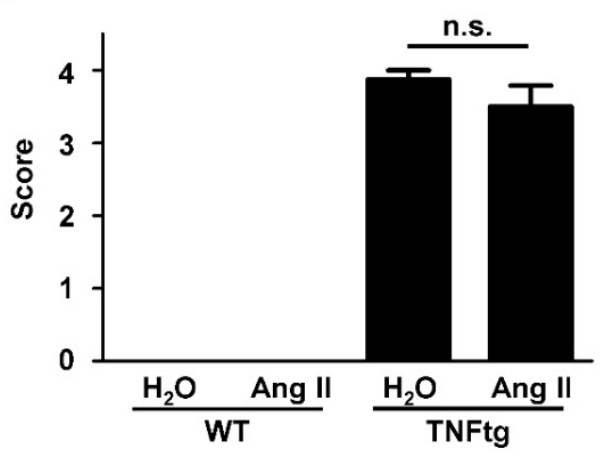

Figure 1. No significant effect of angiotensin II (Ang II) administration on the severity of inflammatory cell infiltration and cartilage damage in tumor necrosis factor-transgenic (TNFtg) mice. Ang II was administered by osmotic pumps to wild-type (WT; $n=6)$ and TNFtg $(n=7)$ male mice from 12 to 16 weeks of age. Water $\left(\mathrm{H}_{2} \mathrm{O}\right)$ was administered by osmotic pumps to WT $(n=6)$ and $\operatorname{TNFtg}(n=4)$ male mice as controls. (A) Quantitative real-time PCR analysis. Agtr1a mRNA expression levels in the right ankle joint tissue were determined. (B) Body weight at the age of 16 weeks. (C) Arthritis scores at the age of 16 weeks. (D) The numbers of arthritic paws with an arthritis score of 2 or higher. (E) Representative images of stained sections around the talus bones of indicated mice; sections were stained with hematoxylin and eosin (H\&E) and Safranin O; original magnification $\times 40$. (F,G) Histological scores of inflammation $(\mathbf{F})$ and cartilage damage $(\mathbf{G})$. Values are the mean \pm SEM. n.s., not significant. ${ }^{*}, p<0.05$. 
2.2. No Significant Effect of Ang II Administration on the Severity of Inflammatory Cell Infiltration in TNFtg Mice

To assess the effect of Ang II on arthritis, exogenous Ang II $(1.44 \mathrm{mg} / \mathrm{kg} /$ day $)$ or water $\left(\mathrm{H}_{2} \mathrm{O}\right)$ was administered by osmotic pumps to the WT and TNFtg mice for 4 weeks. The treatment with Ang II did not significantly alter body weight (Figure 1B), but did induce hypertension (Figure A2). We monitored the severity of paw swelling in each limb during the experimental period. We found that the TNFtg mice exhibited severe swelling of the paws and that the severity of clinical arthritis was not affected by the Ang II infusion. The arthritis score and number of arthritic limbs at the age of 16 weeks are presented in Figure 1C,D.

To analyze the inflamed joints histologically, we performed hematoxylin and eosin (H\&E) and Safranin O staining to determine the inflammatory cell infiltration and cartilage damage. In WT mice, Ang II administration did not cause any detectable histological changes (Figure 1E,F). TNFtg mice exhibited massive inflammatory cell infiltration, and Ang II administration did not affect the severity of inflammation in these mice, which is consistent with the arthritis score results (Figure 1C). Additionally, the severity of cartilage damage, represented by decreased staining of the cartilage matrix, was not affected by the administration of Ang II (Figure 1E,G).

\subsection{Exacerbation of Bone Erosion by Ang II Administration in TNFtg Mice}

We then examined the impact of Ang II on the erosive bone changes of the ankle. Bone erosion around the talus was quantified using micro-computed tomography (CT) and 3D image analysis software. The micro-CT analysis revealed that the destructive bone change was significantly more severe in the Ang II-infused TNFtg mice than in the $\mathrm{H}_{2} \mathrm{O}$-infused TNFtg mice (Figure 2A). This aggravated bone erosion was revealed by the following quantitative analyses: the bone volume (BV) of the talus, the reduction rate of $\mathrm{BV}$, and the eroded volume per repaired volume (Ev/Rpv) of the talus (Figure 2B-D). Tartrate-resistant acid phosphatase (TRAP)-stained images showed slightly increased osteoclast formation in the joints of the Ang II-infused TNFtg mice compared to those in the $\mathrm{H}_{2} \mathrm{O}$-infused TNFtg mice (Figure 2E). Quantitative histological analyses also revealed increased bone erosion and slightly enhanced osteoclast formation around the talus (Figure 2F,G). These findings suggest that Ang II, imported to the joints from circulation, served as an osteoclast-activating factor in the arthritic joint, resulting in enhanced bone erosion without affecting the clinical severity of arthritis. 
A

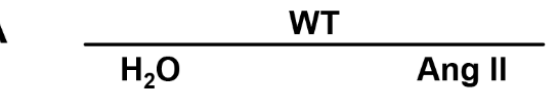

\begin{tabular}{ll}
\multicolumn{2}{c}{ TNFtg } \\
\cline { 2 - 2 } $\mathrm{H}_{2} \mathrm{O}$ & Ang II
\end{tabular}
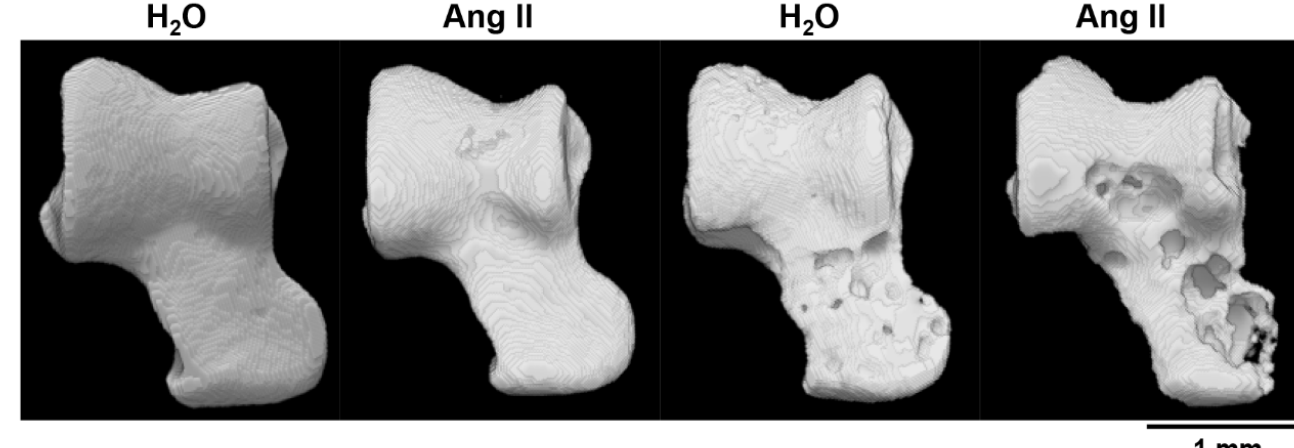

B

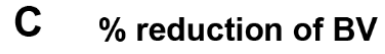

D

Ev/Rpv
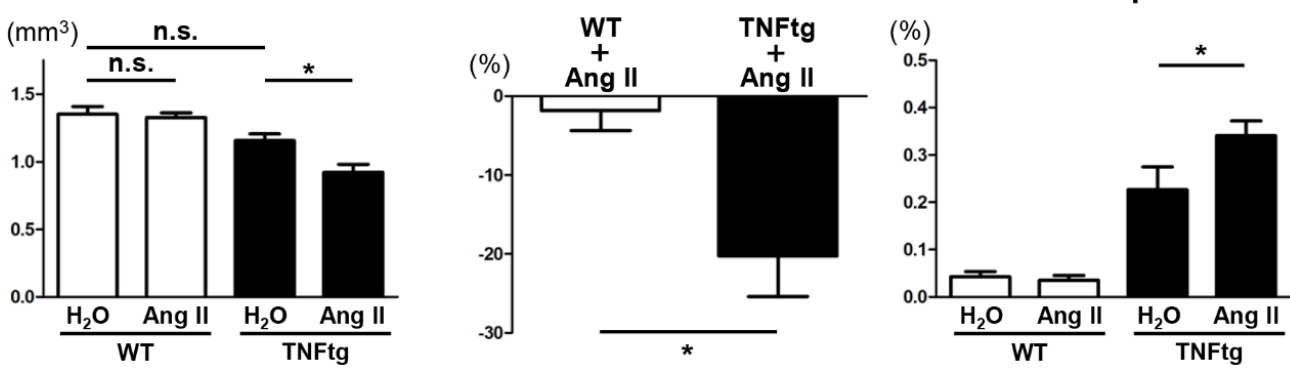

E

WT

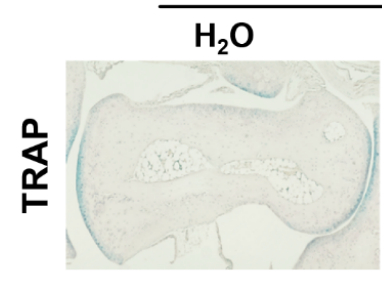

Ang II

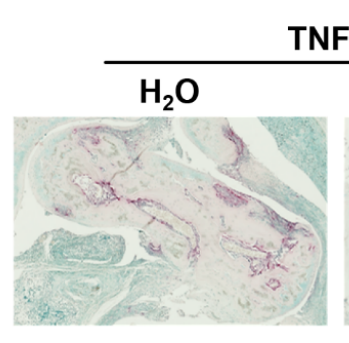

$\mathbf{F}$

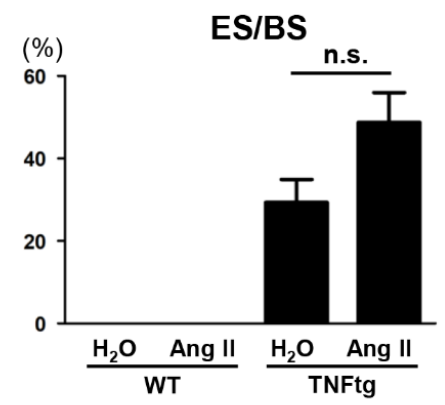

G

N.Oc/BS



Figure 2. Exacerbation of bone erosion by angiotensin II (Ang II) administration in tumor necrosis factor-transgenic (TNFtg) mice. Ang II was administered by osmotic pumps to WT $(n=6)$ and TNFtg $(n=7)$ male mice from 12 to 16 weeks of age. Water $\left(\mathrm{H}_{2} \mathrm{O}\right)$ was administered by osmotic pumps to WT $(n=6)$ and TNFtg $(n=4)$ male mice as controls. (A) Representative 3D micro-computed tomography (CT) images of the talus. (B) Bone volume (BV) of the talus. (C) Rates of reduction in BV of Ang II-infused WT and TNFtg mice relative to $\mathrm{H}_{2} \mathrm{O}$-infused control mice of each genotype. (D) Eroded volume per repaired volume (Ev/Rpv) of the talus. (E) Representative images of tartrate-resistant acid phosphatase (TRAP) staining around the talus bones of indicated mice; original magnification $\times 40$. (F) Eroded surface per bone surface (ES/BS) around the taluses. (G) The number of osteoclasts per bone surface (N.Oc/BS) around the taluses. Values are the mean \pm SEM. n.s., not significant. ${ }^{*}, p<0.05$.

\subsection{No Detectable Changes in the Trabecular and Cortical Bone Parameters with Ang II Administration}

Since both systemic inflammation and excess of Ang II have been reported to decrease the mass of systemic bones $[4,11]$, we examined the bone properties of the tibia and vertebra and determined whether 
Ang II could synergistically enhance inflammation-mediated bone loss in the Ang II-administered arthritic mice. We assessed the tibia trabecular bone (secondary spongiosa, Figure 3A), the tibia cortical bone (midshaft of the tibia, Figure 3B), and the trabecular bone of the spine (fifth lumbar vertebra, Figure $3 \mathrm{C}$ ) using micro-CT. The tibia trabecular bone tended to be decreased in the arthritic mice compared to that in the WT mice, although the difference was not statistically significant in the current set of experiments. The bone reduction rates with Ang II infusion were comparable between WT and TNFtg mice at approximately 30\% (Figure 3D), indicating that the synergistic effect of inflammation and Ang II on osteopenia was not noticeable. In the tibia cortical bone, the presence of arthritis significantly increased bone loss, but the reduction rates with Ang II infusion were comparable between WT and TNFtg mice (Figure 3E). In the vertebral trabecular bone, the presence of arthritis did not significantly affect the bone volume (Figure 3F). Ang II administration tended to decrease bone volume by approximately $10 \%$, but there was no significant difference in the reduction rates between WT and TNFtg mice (Figure 3F). The other analyzed parameters of the trabecular and cortical bones also indicated no significant effect of Ang II administration on bone properties (Figure A3). Collectively, these findings suggest that both inflammation and Ang II tended to decrease bone mass, but there was no apparent synergistic effect on the osteopenic phenotype.

A

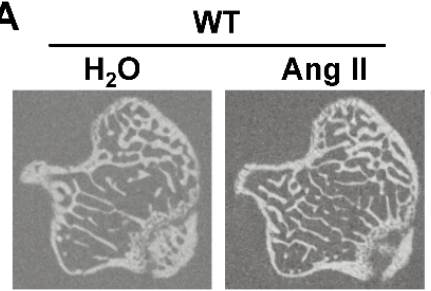

B

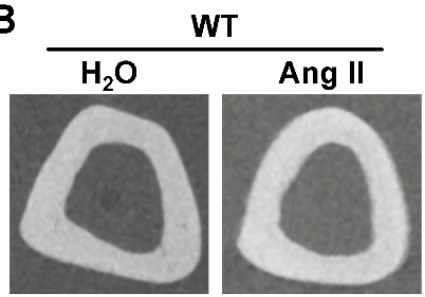

C

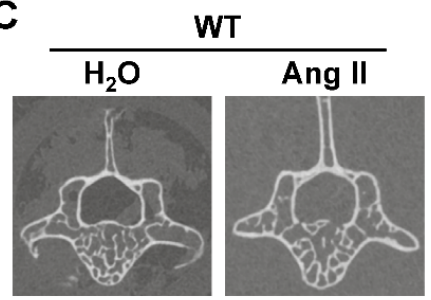

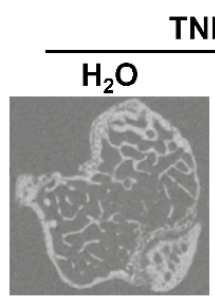

TNFtg

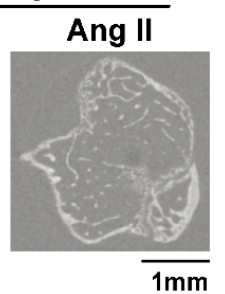

D

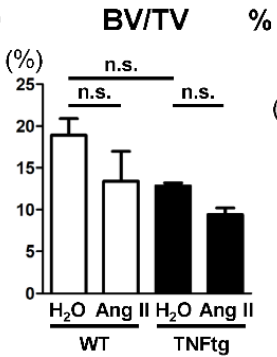

E
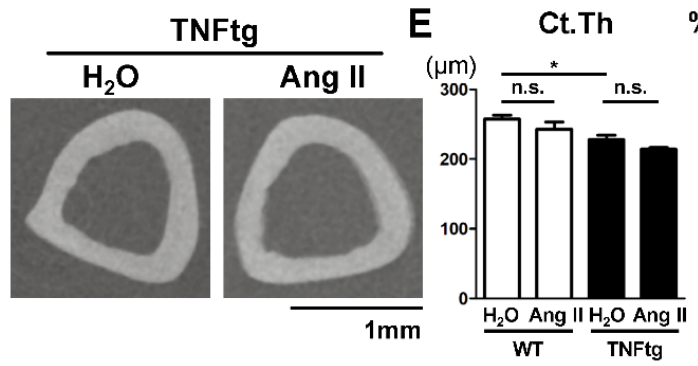

$\%$ reduction of $\mathrm{Ct}$.Th
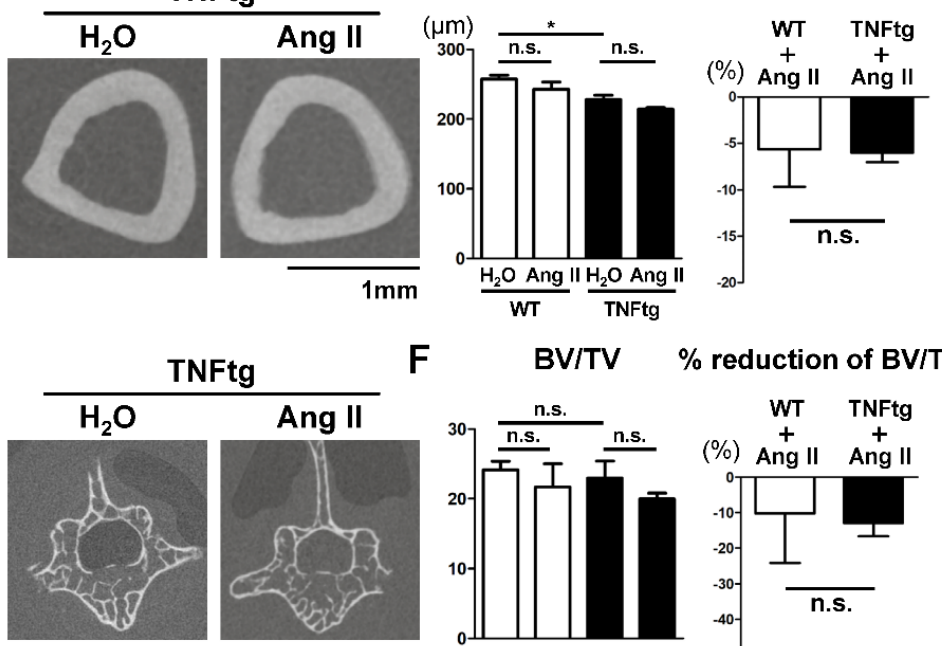

$F$

NFtg

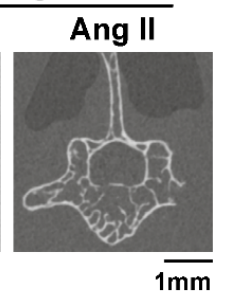

BVITV

\section{$\%$ reduction of BV/TV}

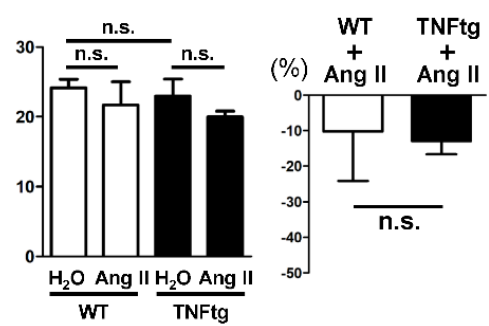

Figure 3. No detectable changes in the trabecular and cortical bone parameters with Ang II administration. Angiotensin II (Ang II) was administered by osmotic pumps to WT $(n=6)$ and tumor necrosis factor-transgenic (TNFtg; $n=7)$ male mice from 12 to 16 weeks old. Water $\left(\mathrm{H}_{2} \mathrm{O}\right)$ was administered by osmotic pumps to WT $(n=6)$ and TNFtg $(n=4)$ male mice as controls. (A-C) Representative 2D micro-CT images of the tibia trabecular bone (A), the tibia cortical bone (B), and the trabecular bone of the spine (the fifth lumbar vertebra) (C). (D) Bone volume per total volume (BV/TV) and reduction rate of the tibia trabecular bone. (E) Cortical thickness (Ct.Th) and reduction rate of the tibia midshaft. (F) Bone volume per total volume (BV/TV) and reduction rate of the fifth lumbar vertebral trabecular bone. Values are the mean \pm SEM. n.s., not significant. ${ }^{*}, p<0.05$. 


\subsection{Effect of AT1R Deficiency on the Severity of Inflammatory Cell Infiltration in TNFtg Mice}

Since an excess of exogenous Ang II accelerated inflammatory bone destruction (Figure 2A), we investigated whether endogenous Ang II could play a role in bone destruction using AT1R-deficient

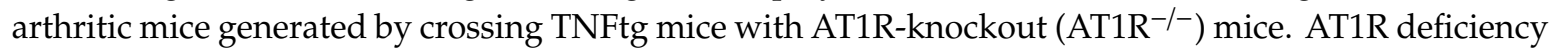
did not significantly alter body weight (Figure $4 \mathrm{~A}$ ). We found that the severity of clinical arthritis (Figure 4B,C) and the extent of inflammatory cell infiltration (Figure 4D,E) were comparable between TNFtg and TNFtg/AT1R ${ }^{-/}$mice. In addition, the severity of cartilage damage was not affected by AT1R deficiency (Figure 4D,F).
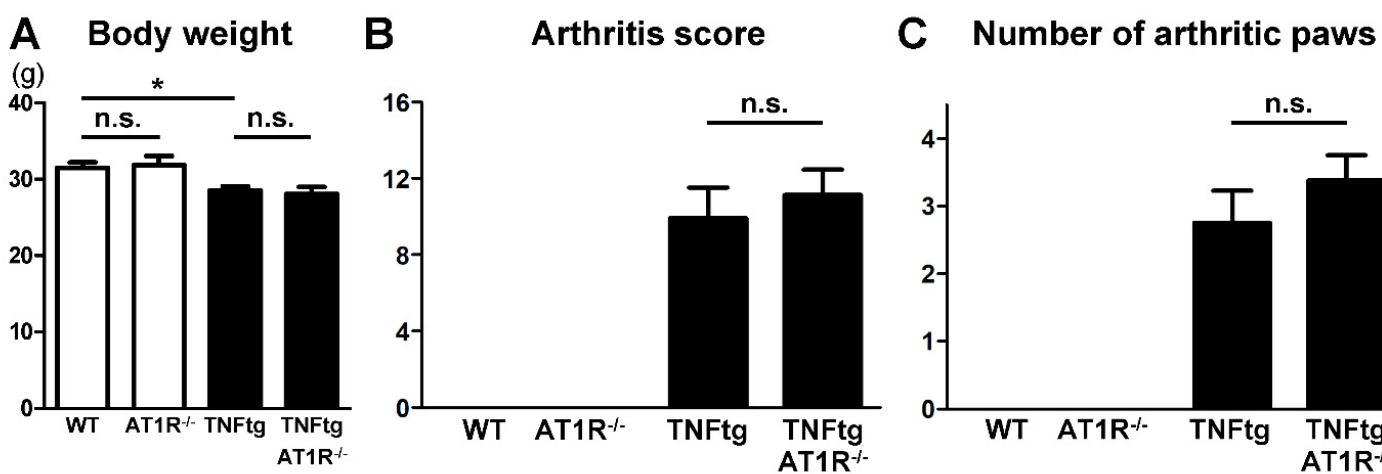

D WT

AT1 $R^{-1-}$

TNFtg
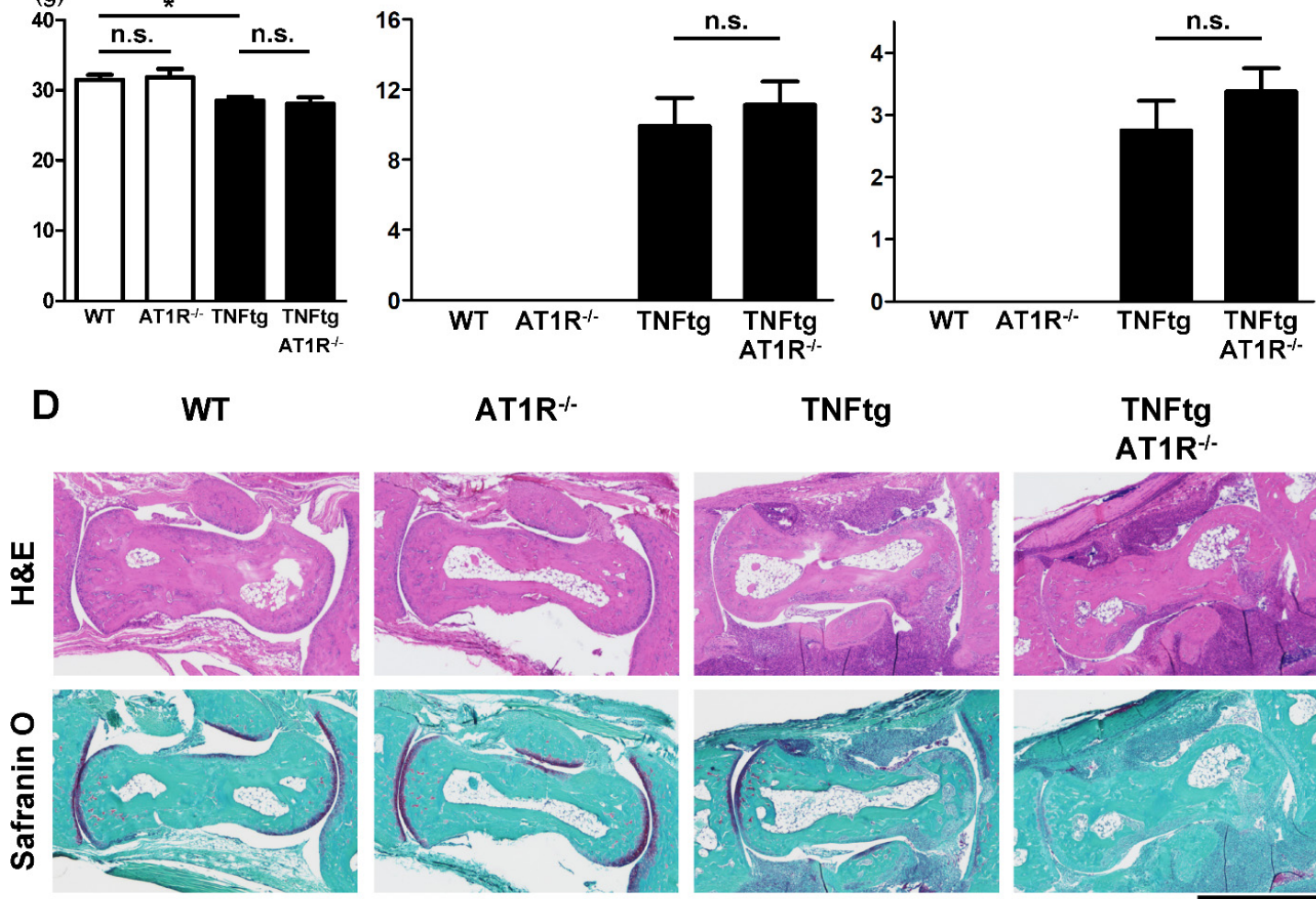

E

Inflammation
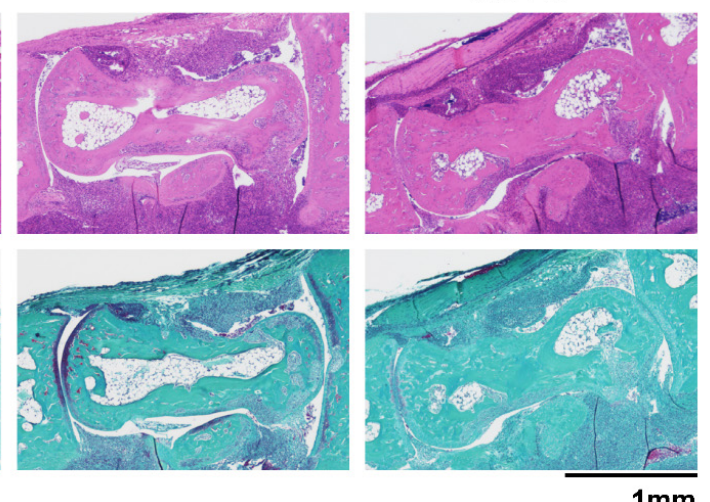

F

Cartilage damage
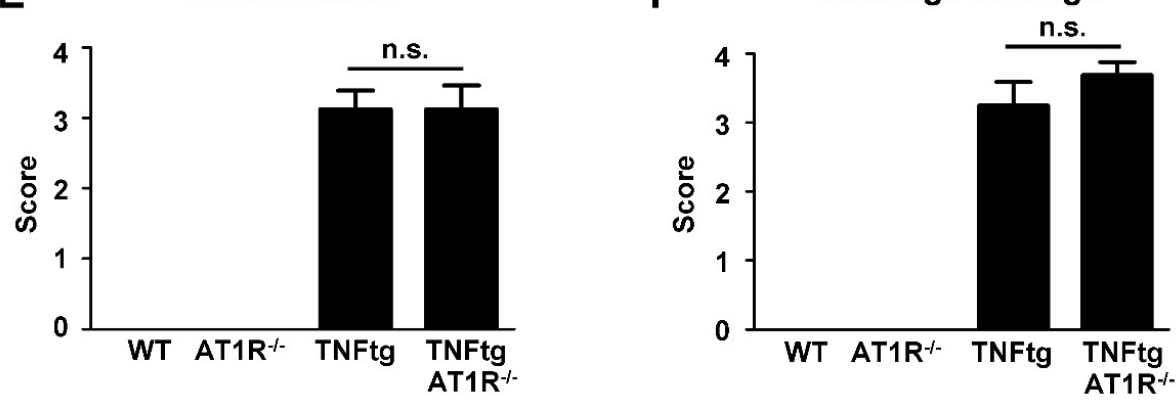

Figure 4. Effect of angiotensin II type 1 receptor (AT1R) deficiency on the severity of inflammatory cell infiltration in tumor necrosis factor-transgenic (TNFtg) mice. TNFtg mice were crossed with

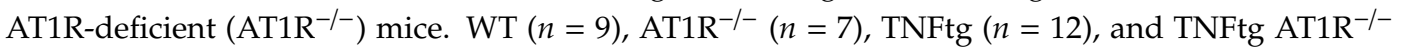
$(n=8)$ male mice were analyzed at the age of 16 weeks. (A) Body weight at the age of 16 weeks. (B) Arthritis score at the age of 16 weeks. (C) The number of arthritic paws with an arthritis score of 2 or higher. (D) Representative images of stained sections around the talus bones of indicated mice; sections were stained with hematoxylin and eosin (H\&E) and Safranin O; original magnification $\times 40$. $(\mathbf{E}, \mathbf{F})$ Histological scores of inflammation $(\mathbf{E})$ and cartilage damage $(\mathbf{F})$. Values are the mean \pm SEM. n.s., not significant. ${ }^{*}, p<0.05$. 


\subsection{Influence of AT1R Depletion on Bone Erosion in TNFtg Mice}

We next examined whether the deletion of AT1R could reduce bone destruction in the arthritic mice. Micro-CT analysis of the ankle joints revealed that TNFtg/AT1R ${ }^{-/}$mice exhibited the same extent of severe bone loss as TNFtg mice (Figure 5A,B). Additionally, the BV reduction rate and the erosive volume (Ev/Rpv) of the talus in the TNFtg/AT1R ${ }^{-/-}$mice were comparable to those in the TNFtg mice (Figure 5C,D). These findings indicate that AT1R deficiency did not alleviate the destructive bone changes in the inflammatory joints of the arthritic mice. Histological analyses revealed that the extents of bone erosion and osteoclast formation were comparable between TNFtg and TNFtg/AT1R ${ }^{-/-}$mice (Figure 5E-G).
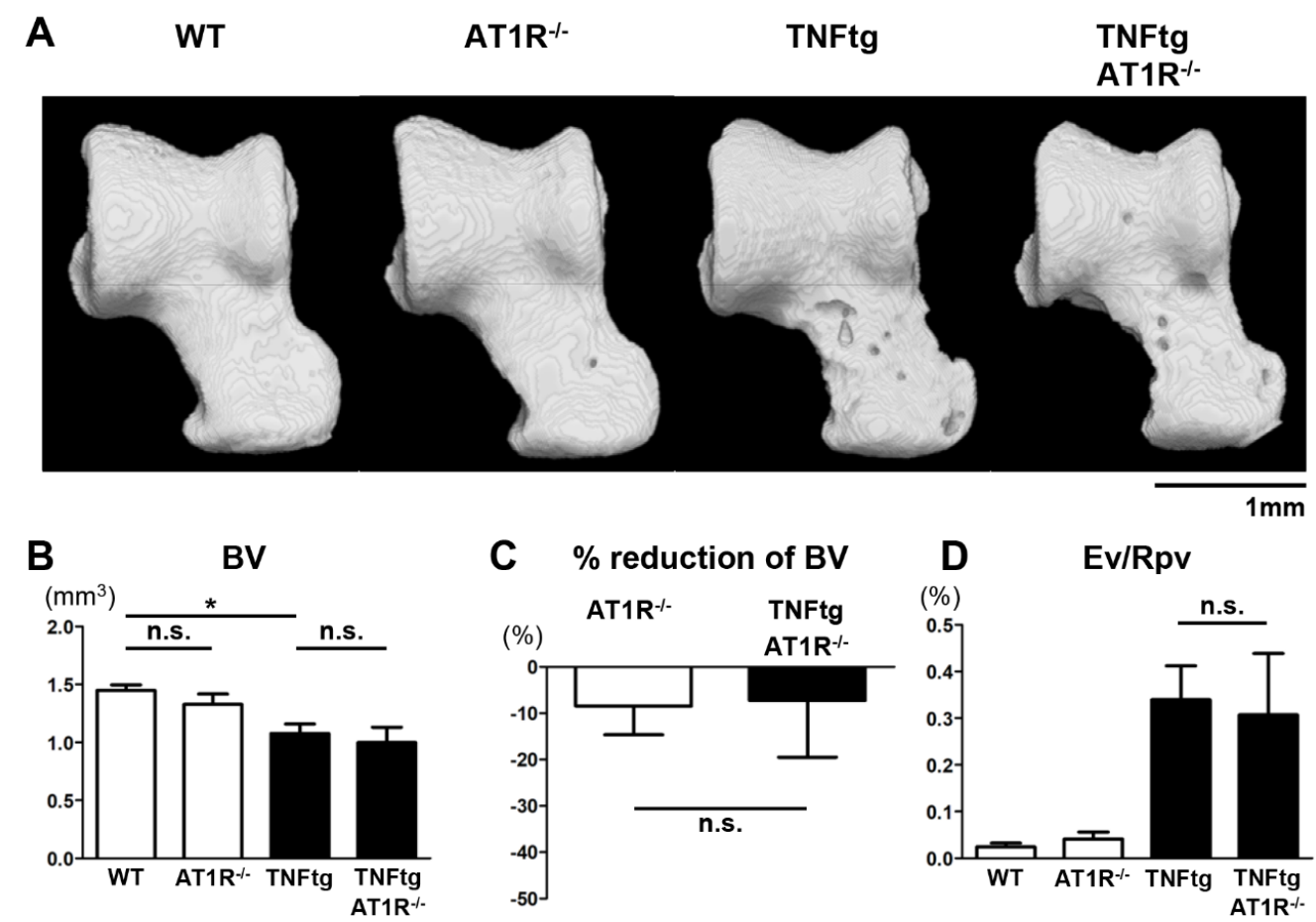

C \% reduction of $\mathrm{BV}$
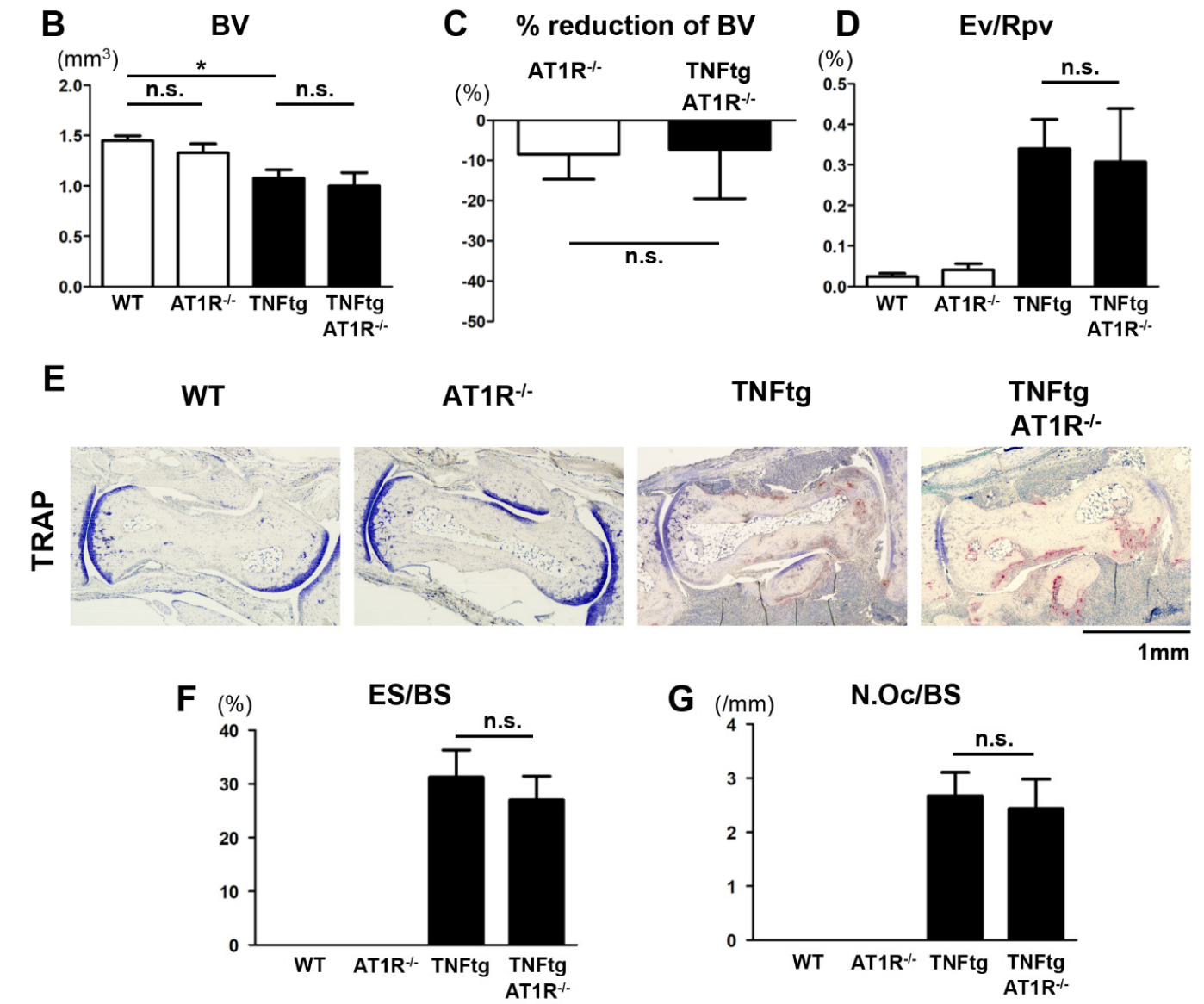

Figure 5. Influence of AT1R depletion on bone erosion in tumor necrosis factor-transgenic (TNFtg) mice. TNFtg mice were crossed with AT1R-deficient $\left(\mathrm{AT}^{-1-} \mathrm{R}^{--}\right)$mice. WT $(n=9),{\operatorname{AT} 1 \mathrm{R}^{-/}}^{-}(n=7), \mathrm{TNFtg}$ $(n=12)$, and TNFtg AT1R ${ }^{-/-}(n=8)$ male mice were analyzed at the age of 16 weeks. (A) Representative $3 \mathrm{D}$ micro-CT images of the talus. (B) Bone volume (BV) of the talus. (C) Rate of reduction in BV by 
AT1R deficiency relative to that in the control mice of each genotype. (D) Eroded volume per repaired volume (Ev/Rpv) of the talus. (E) Representative images of tartrate-resistant acid phosphatase (TRAP) staining around the talus bones of indicated mice; original magnification $\times 40$. (F) Eroded surface per bone surface (ES/BS) around the taluses. (G) The number of osteoclasts per bone surface (N.Oc/BS) around the taluses. Values are the mean \pm SEM. n.s., not significant. ${ }^{*}, p<0.05$.

\subsection{Effect of AT1R Deficiency on Bone Properties of the Trabecular and Cortical Bones in TNFtg Mice}

$\mathrm{AT}_{1} \mathrm{R}^{-/-}$mice were previously reported to exhibit an increased trabecular BV and increased trabecular number and connectivity [16]. To examine the effect of AT1R deficiency on the bone volume of systemic bones in the arthritic condition, we analyzed the bone properties of the tibia and vertebra of the TNFtg arthritic mice using micro-CT (Figure 6A-C). The TNFtg mice exhibited a significant reduction in BV/TV of the tibia and the AT1R deficiency modestly alleviated the bone loss caused by arthritis, even though the difference between TNFtg and TNFtg/AT1R ${ }^{-/}$mice was not statistically significant (Figure 6D). A similar insignificant tendency was observed in the vertebral trabecular bone (Figure 6F). In the tibia cortical bone, AT1R deficiency did not show any protective effect on bone loss (Figure 6E). The other analyzed parameters of the trabecular and cortical bones also indicated no significant effect of AT1R deficiency on bone properties (Figure A4). These findings suggest that the inhibition of endogenous Ang II has a limited protective effect on bone loss in arthritic mice.

A

A wT

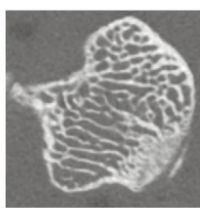

B

WT

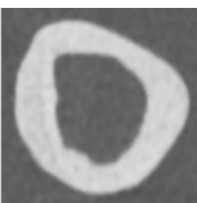

C
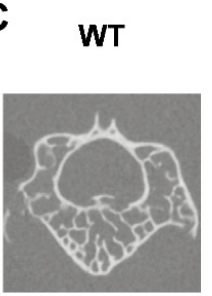

AT1R $^{-1-}$



AT1R $^{-1-}$

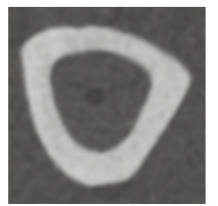

AT1R $^{-1-}$

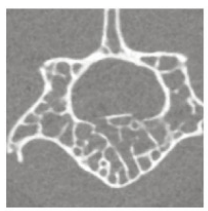

TNFtg

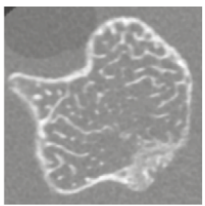

TNFtg

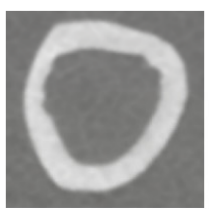

TNFtg

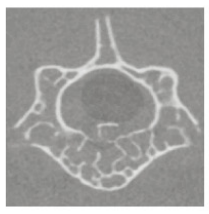

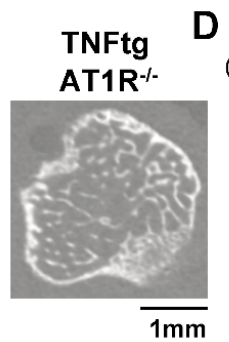


$\mathbf{F}$



$\%$ reduction of $\mathrm{BV} / \mathrm{TV}$

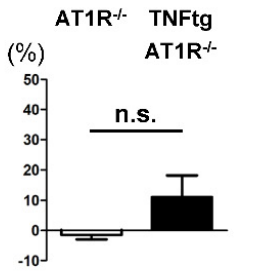

Figure 6. Effect of AT1R deficiency on bone properties of the trabecular and cortical bones in tumor necrosis factor-transgenic (TNFtg) mice. TNFtg mice were crossed with AT1R-deficient (AT1R ${ }^{-/}$) mice.

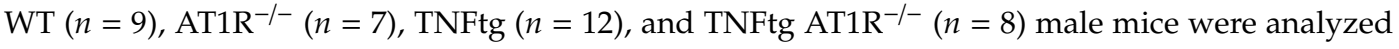
at the age of 16 weeks. Representative $2 \mathrm{D}$ micro-CT images of the tibia trabecular bone (A), the tibia cortical bone (B), and the trabecular bone of the spine (fifth lumbar vertebra) (C). (D) Bone volume per total volume (BV/TV) and reduction rate of the tibia trabecula bone. (E) Cortical thickness (Ct.Th) and reduction rate of the tibia midshaft. (F) Bone volume per total volume (BV/TV) and reduction rate of the fifth lumbar vertebral trabecular bone. Values are the mean \pm SEM. n.s., not significant. ${ }^{*}, p<0.05$. 


\section{Discussion}

In this study, we sought to clarify the impact of excessive Ang II and inhibition of the endogenous RAS on bone erosion and systemic bone loss in a TNF-mediated arthritic condition. We found that the administration of Ang II enhanced destructive bone changes in inflammatory joints without affecting the severity of inflammation. There was no noticeable synergistic effect of Ang II administration and inflammation on osteopenia of the tibia and vertebra in mice. Further, we found that AT1R deficiency had a minimal protective effect on bone erosion and systemic bone loss in the arthritis model.

Interestingly, we observed that the administration of Ang II aggravated joint destruction in the arthritic mice. Ang II has been reported to enhance systemic bone loss in murine osteoporosis models [11,17]. Ang II induces RANKL expression in osteoblasts and subsequently enhances osteoclastogenesis, resulting in systemic bone loss [6,11]. However, no previous studies have explored the role of the RAS in the development of bone erosion in an arthritis model. In rheumatoid arthritis, inflammatory cytokines such as TNF increase RANKL expression in synoviocytes and subsequently promote osteoclastic differentiation and activation, resulting in erosive bone changes in joints [2]. Our results demonstrate that excessive Ang II could exacerbate the TNF-induced inflammatory joint destruction associated with increased osteoclast formation.

The current study has important clinical implications for the management of rheumatoid arthritis. Our findings suggest that in patients in whom the local effect of Ang II is upregulated via increased imported Ang II from circulation, joint destruction can be promoted as a consequence of systemic RAS activation. Systemic activation of the RAS can be observed in several pathological conditions, such as renal artery stenosis, congestive heart failure, cardiac hypertrophy, chronic kidney disease, and obesity $[18,19]$. Such pathological conditions could be risk factors for progressive joint destruction in inflammatory arthropathies.

Although Ang II appeared to promote bone erosion in inflamed joints, its effects on systemic bones, represented by the tibia and vertebra, were found to be very limited. There are several possible explanations for this. Firstly, in the arthritic joints of mice, other inflammatory cytokines such as IL-1 and IL-6 are highly produced [2,20]. In addition to TNF, these other osteoclast-activating factors might play important synergistic roles in the Ang II-promoted bone erosion in joints. Secondly, the expression of AT1R was significantly increased in the arthritic joints (Figure 1A). This could contribute to hyper-responsiveness to Ang II, resulting in increased osteoclastic bone destruction in the joints. Thirdly, the exposure period to Ang II (4 weeks in this study) might be too short for this effector to exert an osteopenic effect on systemic bones. Indeed, a previous study showed a significant osteopenic effect of excessive RAS activation in 6-month-old Tsukuba hypertensive mice that were continuously exposed to excessive Ang II via transgenes encoding human renin and human angiotensinogen [17].

Since the expression of AT1R was increased in the arthritic joints of the TNFtg mice (Figure 1A), we assumed that AT1R deficiency would ameliorate bone erosion in this arthritis model. Contrary to our expectation, AT1R deficiency did not significantly improve the erosive bone changes in the TNFtg mice. These data indicate a limited role of the local RAS during the process of joint destruction in this arthritic model. The RAS might modulate bone mass only under pathological conditions with excessive systemic activation. Analyses of AT1R-deficient arthritic mice with excessive Ang II would be needed to verify this concept.

The limitation of our study is that the precise mechanisms through which Ang II enhances bone erosion are unclear. We have tested the effect of Ang II on osteoclast differentiation in murine primary bone marrow-derived macrophage cultures. Ang II stimulation did not promote osteoclast formation in the mono-culture of bone marrow-derived macrophage (Figure A5A,B), whereas Ang II enhanced osteoclast formation in the co-culture system with osteoblasts (Figure A5C,D). These data suggest that Ang II promotes osteoclast formation indirectly via stromal cells. In support of this notion, Ang II has been previously reported to induce RANKL expression in stromal cells [17]. Various cells can express RANKL in arthritic joints, synovial cells, osteoblasts, or osteocytes, which might be attributed to the 
Ang II-mediated bone erosion. Other possibilities are that Ang II regulates angiogenesis in arthritic joints or that Ang II modulates cellular functions via the Ang II type 2 receptor, which reportedly regulates inflammation in the arthritic synovium [21]. Further research will be required to clarify the underlying mechanisms.

Another possible limitation of this study is the relatively small sample sizes which may have insufficient statistical power to detect a small difference in some comparisons. For instance, a statistically significant difference was not detected in the trabecular BV/TV of the tibia between $\mathrm{H}_{2} \mathrm{O}$-treated WT $(n=6)$ and $\mathrm{H}_{2} \mathrm{O}$-treated TNFtg $(n=4)$ mice (Figure 3D), although there is a statistically significant difference between WT $(n=9)$ and TNFtg $(n=12)$ mice in the AT1R ${ }^{-1}$ strain (Figure $\left.6 \mathrm{D}\right)$. Post-hoc power analyses have shown that a larger sample size would be needed to detect a substantial difference in Figure 3D. Therefore, future studies with larger sample sizes would be necessary to detect a small but significant difference.

We previously reported that the RAS is involved in vascular damage and that AT1R blockers have potent vascular protective effects in an arthritis model [22]. Therefore, in patients with rheumatoid arthritis complicated by RAS-dependent hypertension, the blockade of the RAS might be beneficial not only to reduce blood pressure and vascular damage but also to prevent bone erosion.

In conclusion, this study provides novel insights into the pathophysiological function of Ang II in the regulation of inflammatory bone destruction. In patients with rheumatoid arthritis, the systemically activated RAS in concurrent pathological conditions could be involved in the progression of joint destruction in conjunction with increased local expression of AT1R. The effects of pharmacological inhibition of the Ang II-mediated pathway on bone erosion remain unclear but warrant further clinical examination.

\section{Materials and Methods}

\subsection{Mice}

Human TNFtg mice (C57BL/6 background) were obtained (\#1006; Taconic Biosciences, Hudson, NY, USA). The TNFtg heterozygous mice spontaneously develop arthritis on the fore and hind paws at approximately 8 weeks of age, and arthritis progresses with age [23]. AT1R-knockout mice (AT1R ${ }^{-/-}$; C57BL/6 background) were obtained (\#002682; The Jackson Laboratory, Bar Harbor, ME, USA) [24] and crossed with TNFtg mice to generate AT1R-deficient arthritic mice. Age- and sex-matched littermates were used as control mice. All mutant mice were maintained in the animal facility of Kawasaki Medical School (Okayama, Japan) and were housed in a group (2-5 mice per cage) and maintained at $22{ }^{\circ} \mathrm{C}$ under $12 \mathrm{~h} \mathrm{light} / 12 \mathrm{~h}$ dark cycles with free access to water and standard laboratory food. All animal experiments were approved by the Institutional Safety Committee for Recombinant DNA Experiments (Nos. 14-40, 14-41, and 19-27, which are approved on 3/13/2015, 3/13/2015, and 10/17/2019, respectively) and the Institutional Animal Care and Use Committee of Kawasaki Medical School (Nos. 17-129, 18-057, and 18-130, which are approved on 2/1/2018, 4/1/2018, and 2/1/2019, respectively). All experimental procedures were conducted in accordance with institutional and NIH guidelines for the humane use of animals.

\subsection{Ang II Infusion Model}

Twelve-week-old WT and TNFtg male mice were randomly divided into two groups that were infused with either water $\left(\mathrm{H}_{2} \mathrm{O}\right)$ or Ang II, which was dissolved in $\mathrm{H}_{2} \mathrm{O}$. Ang II was administered by osmotic pumps to WT $(n=6)$ and TNFtg mice $(n=7)$ from 12 to 16 weeks of age. $\mathrm{H}_{2} \mathrm{O}$ was administered by osmotic pumps to WT $(n=6)$ and TNFtg mice $(n=4)$ as controls. The mice were anesthetized, and an osmotic pump containing $100 \mu \mathrm{L}$ of either $\mathrm{H}_{2} \mathrm{O}$ or Ang II (Sigma-Aldrich, St. Louis, MO, USA) was implanted subcutaneously as previously described [22,25]. Ang II was continuously infused at a dose of $1.44 \mathrm{mg} / \mathrm{kg} /$ day from 12 to 16 weeks of age. Arterial blood pressure was measured by the tail-cuff method with a pulse transducer (BP98-A; Softron, Tokyo, Japan), as reported [26]. Mice were 
monitored for signs of arthritis in a blinded manner, and each limb was individually scored on a scale of $0-4$. Scores were assigned based on the extent of erythema or swelling present in each limb, assigning a maximum score of 16 per mouse, as described previously [27,28]. Mice were monitored until the age of 16 weeks, and then serum, hind limb, and spine (the fifth lumbar vertebra) samples were collected.

\subsection{Micro-Computed Tomography (CT) Analysis}

Bone samples were fixed in $4 \%$ paraformaldehyde (PFA) in phosphate-buffered saline for 2 days, and PFA-fixed bone samples were immersed in 70\% ethanol. Three-dimensional microarchitecture of the talus, tibia, and spine was evaluated by using a micro-CT system (Ele Scan mini; Nittetsu Elex, Tokyo, Japan) with an X-ray energy of $45 \mathrm{kVP}(145 \mu \mathrm{A})$, as described previously [29,30]. The voxel resolution of all bone images was $15 \mu \mathrm{m}$. The bone properties of the tibia and the fifth lumbar vertebra, and bone erosion of the ankle (talus bones) were analyzed using analysis software (TRI/3D-BON; Ratoc System Engineering Co. Ltd., Tokyo, Japan). The analyzed region of the tibia trabecular bone comprised 67 slices of secondary spongiosa adjacent to the primary spongiosa (starting $0.5 \mathrm{~mm}$ from the distal border of the growth plate), that of the vertebra comprised the entire fifth lumbar vertebral body area (approximately 140 slices), and that of the tibia cortical bone comprised 33 slices of the midshaft (1 mm proximal region from the tibiofibular junction). The micro-CT parameters of the tibia and spine were described according to international guidelines [31]. The talus bones were evaluated using BV and Ev/Rpv for quantitative measurements of bone erosion [32]. Ev/Rpv on the whole talus was calculated automatically with the software according to the software program (TRI/3D-BON). We set the concave surface search range up to $0.15 \mathrm{~mm}$, and the absorption surface extraction radius of curvature was $960 \mu \mathrm{m}$ or less as described previously [33].

\subsection{Histological Analysis}

The hind limbs were decalcified in $10 \%$ EDTA (pH 7.2) at $4{ }^{\circ} \mathrm{C}$ for 4 weeks and subsequently embedded in paraffin. Sections $(3 \mu \mathrm{m})$ were stained with hematoxylin and eosin $(\mathrm{H} \& \mathrm{E})$ and Safranin O. The severity of inflammation and cartilage damage around the talus bone was scored on a scale of 0-4 under blinded conditions as described previously $[27,28]$. TRAP staining was performed to visualize osteoclast formation, and the sections were counterstained with methyl green. Histological analyses were performed using a BZ-X analyzer (Keyence, Osaka, Japan). The eroded surface per bone surface (ES/BS) and the number of osteoclasts per bone surface (N.Oc/BS) around the taluses were determined.

\subsection{Real-Time Quantitative Polymerase Chain Reaction ( $q P C R$ )}

qPCR was performed as described previously [30,34]. Total RNA was extracted from the right ankle joint using RNAiso Plus (Takara Bio, Shiga, Japan) and solubilized in ribonuclease (RNase)-free water. Complementary DNA (cDNA) was synthesized using the Prime Script RT reagent Kit (Takara Bio). qPCR reactions were performed using SYBR Green PCR Master Mix (Takara Bio) with the StepOnePlus Real-Time PCR System (Thermo Fisher Scientific, Waltham, MA, USA). Gene expression levels relative to Gapdh were calculated by the $\Delta \Delta \mathrm{Ct}$ method and normalized to control samples obtained from the WT mice. The qPCR analysis used the following primers: $5^{\prime}$-taccagctctgcggctct- $3^{\prime}$ and $5^{\prime}$-gccagccatttt ataccaatct-3' for Agtr1a (AT1R); 5'-atcaagaaggtggtgaagca-3' and 5'-gacaacctggtcctcagtgt-3' for Gapdh. All qPCR reactions yielded products with single peak dissociation curves.

\subsection{Statistical Analysis}

All values are given as the mean \pm standard error of the mean (SEM). A two-tailed unpaired Student's $t$-test was used to compare two groups, and a one-way analysis of variance (ANOVA) followed by Tukey's post-hoc test was used to compare three or more groups by using GraphPad Prism 5 (GraphPad Software, San Diego, CA, USA). $p$ values lower than 0.05 were considered statistically significant. 


\title{
4.7. Supplementary Methods
}

Additional Supporting Information can be found online in the Supplementary Materials tab for this article.

Supplementary Materials: Supplementary materials can be found at http:/www.mdpi.com/1422-0067/21/11/ 4145/s1.

Author Contributions: Conceptualization, T.A., T.M. (Tomoyuki Mukai), and Y.M.; formal analysis, T.A., T.M. (Tomoyuki Mukai), and T.M. (Takafumi Mito); funding acquisition, T.M. (Tomoyuki Mukai) and Y.M.; investigation, T.M. (Tomoyuki Mukai); methodology, T.A. and T.M. (Tomoyuki Mukai); project administration, T.M. (Tomoyuki Mukai); software, T.A.; supervision, T.M. (Tomoyuki Mukai) and Y.M.; validation, T.A., T.M. (Tomoyuki Mukai), K.K., S.T., S.F., H.A.U., and Y.M.; writing一original draft, T.A., T.M. (Tomoyuki Mukai), and Y.M.; writing-review and editing, T.A., T.M. (Tomoyuki Mukai), T.M. (Takafumi Mito), K.K., S.T., S.F., H.A.U., and Y.M. All authors have read and agreed to the published version of the manuscript.

Funding: This work was supported by grants from JSPS KAKENHI (20K08814 and 17K09991 to Y.M.), Kawasaki Medical School (Research Project Grants; R01-060 and 30-051 to Y.M.), and UCB Japan (T.M., Tomoyuki Mukai).

Acknowledgments: We would like to thank M. Sato and H. Nagasu (Department of Nephrology and Hypertension, Kawasaki Medical School), Y. Jyu (Department of Health and Sports Sciences, Kawasaki University of Medical Welfare), and T. Sone (Department of Nuclear Medicine, Kawasaki Medical School) for technical assistance and critical suggestions; Y. Mino, M. Yoshimoto, K. Maitani, A. Kusumoto, H. Nakashima, N. Takemasa, and N. Obara for their technical assistance; and N. Nango (Ratoc System Engineering Co., Ltd.) for his kind instruction regarding the micro-CT analysis software. We are also indebted to N. Iwachidou and the staff at the Research Center of Kawasaki Medical School. We are especially grateful to David A. Fox (University of Michigan, Ann Arbor, MI) for critically reading the manuscript.

Conflicts of Interest: T.A., T.M. (Tomoyuki Mukai), T.M. (Takafumi Mito), K.K., S.T., S.F., and Y.M. received scholarship donations from Takeda Pharmaceutical Co., Astellas Pharma Inc., Merck \& Co., Daiichi Sankyo Inc., Shionogi \& Co., Chugai Pharmaceutical Co., and AYUMI Pharmaceutical Co. H.A.U. belongs to the Department of Chronic Kidney Disease and Cardiovascular Disease, which is endowed by Kawanishi Holdings, Chugai pharmaceutical Co., Boehringer Ingelheim $\mathrm{GmbH}$, and Terumo Co. The funders had no role in the design of the study; the collection, analyses, or interpretation of data; the writing of the manuscript; or in the decision to publish the results.

\section{Abbreviations}

\author{
Ang II Angiotensin II \\ TNF Tumor necrosis factor \\ TNFtg Tumor necrosis factor-transgenic \\ AT1R Angiotensin II type 1 receptor \\ WT Wild-type
}


Appendix A

A

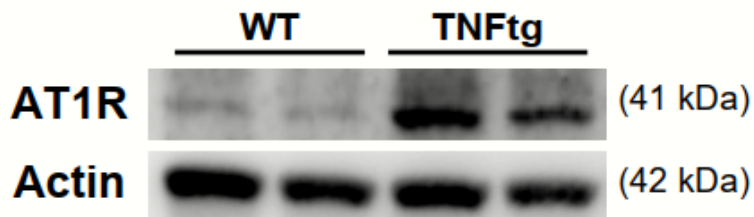

B

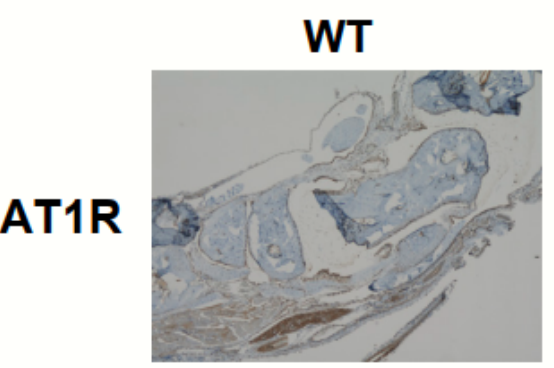

TNFtg

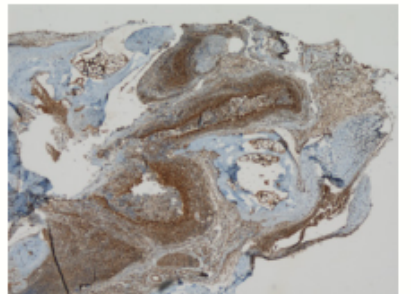

Negative control

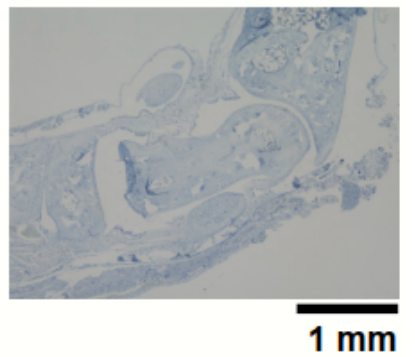

Figure A1. The protein expression of angiotensin II type 1 receptor (AT1R) in the joint tissues was increased in tumor necrosis factor-transgenic (TNFtg) mice. (A) Western blot analysis of AT1R expression in the fore paw tissues. The fore paw samples were obtained from 16-week-old wild-type (WT) and TNFtg mice. (B) Immunohistochemistry staining images of AT1R. The expression of AT1R in the left ankle joint specimens was determined. Original magnification $\times 40$. A tissue specimen processed without the primary antibody is presented as a negative control. Detailed methods are described in the Supporting Information.


Figure A2. Systolic blood pressure in wild-type (WT) and tumor necrosis factor-transgenic (TNFtg) mice administered angiotensin II (Ang II) and water $\left(\mathrm{H}_{2} \mathrm{O}\right)$. Ang II was administered by osmotic pumps to WT and TNFtg mice from 12 to 16 weeks of age. Values are the mean \pm SEM. ${ }^{*}, p<0.05$ (WT (Ang II) vs. WT $\left(\mathrm{H}_{2} \mathrm{O}\right)$ ). n.s., not significant (TNFtg (Ang II) vs. TNFtg $\left(\mathrm{H}_{2} \mathrm{O}\right)$ ). 
A

Mineralization density

Tb.Th

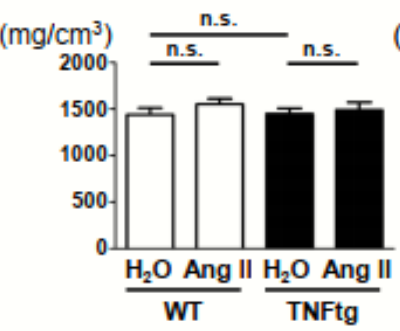

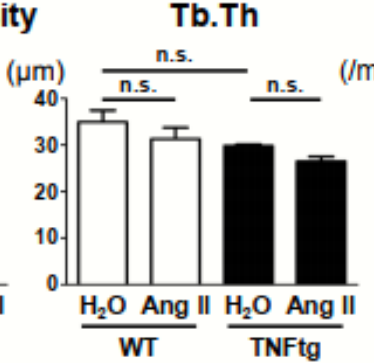
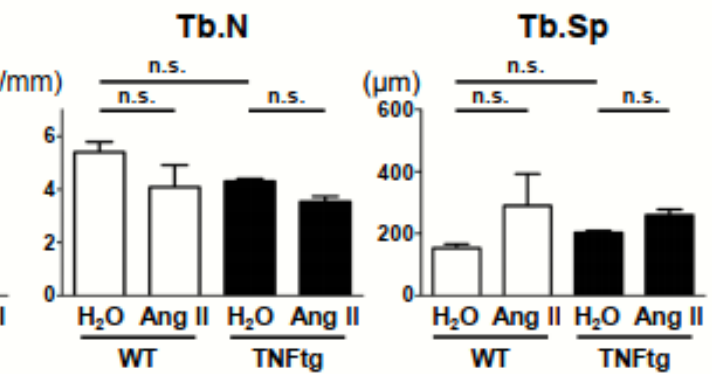

B

Tt.Ar

Ct.Ar
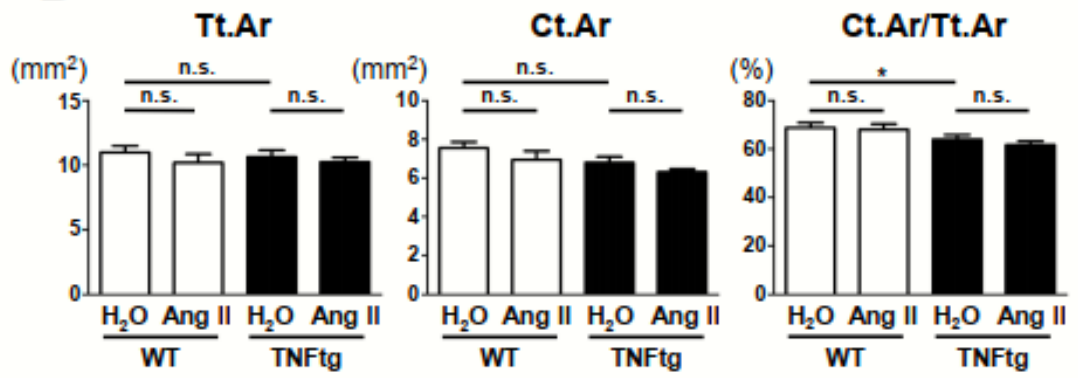

C

Mineralization density

Tb.Th

Tb.N

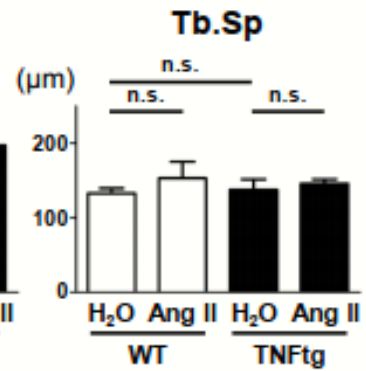

Figure A3. Trabecular and cortical bone parameters in wild-type (WT) and tumor necrosis factor-transgenic (TNFtg) mice administered angiotensin II (Ang II) and water $\left(\mathrm{H}_{2} \mathrm{O}\right)$. Ang II was administered by osmotic pumps to WT $(n=6)$ and TNFtg $(n=7)$ male mice from 12 to 16 weeks of age. $\mathrm{H}_{2} \mathrm{O}$ was administered by osmotic pumps to WT $(n=6)$ and TNFtg $(n=4)$ male mice as controls. (A) Trabecular bone parameters of the tibia. (B) Cortical bone parameters of the tibia midshaft. (C) Trabecular bone parameters of the spine (fifth lumbar vertebra). Tb.Th, trabecular thickness; Tb.N, trabecular number; Tb.Sp, trabecular separation; Tt.Ar, total cross-sectional area inside the periosteal envelope; $\mathrm{Ct}$.Ar, cortical cross-sectional area. Values are the mean \pm SEM. n.s., not significant. *, $p<0.05$. 


\section{A}

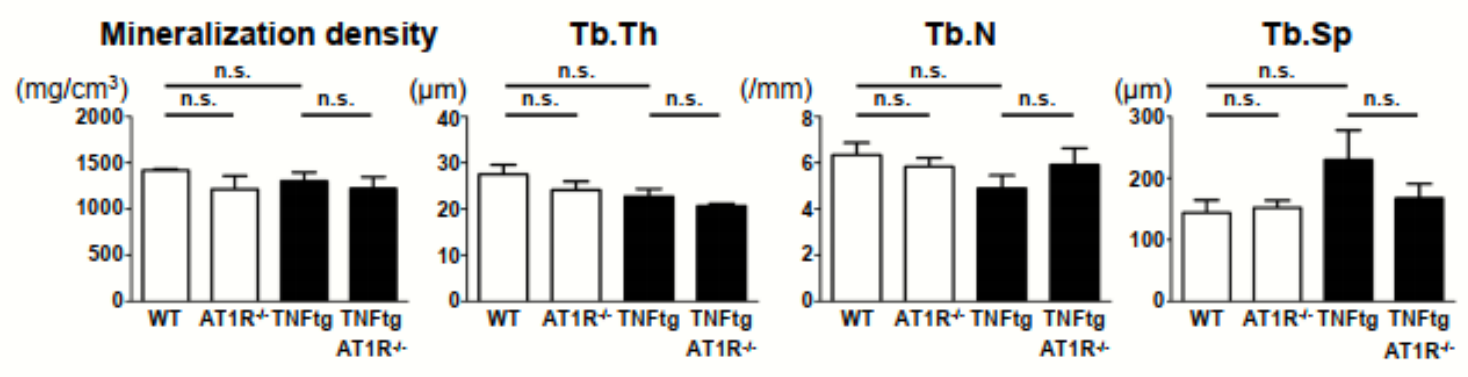

B
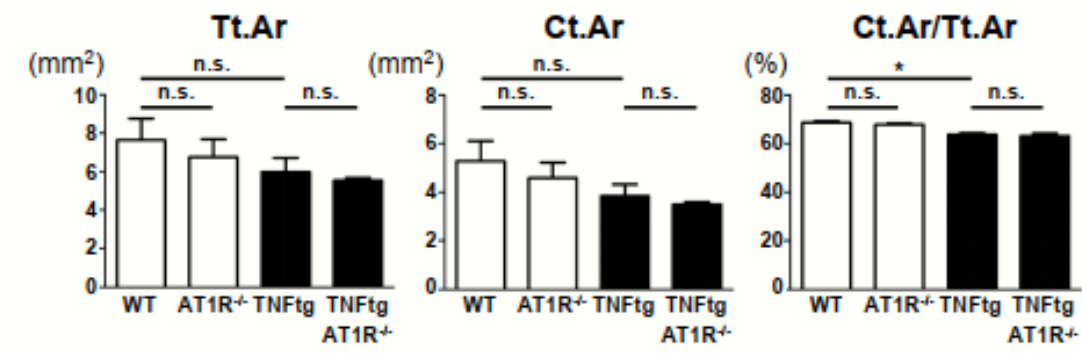

\section{C}

Mineralization density

Tb.Th

Tb.N
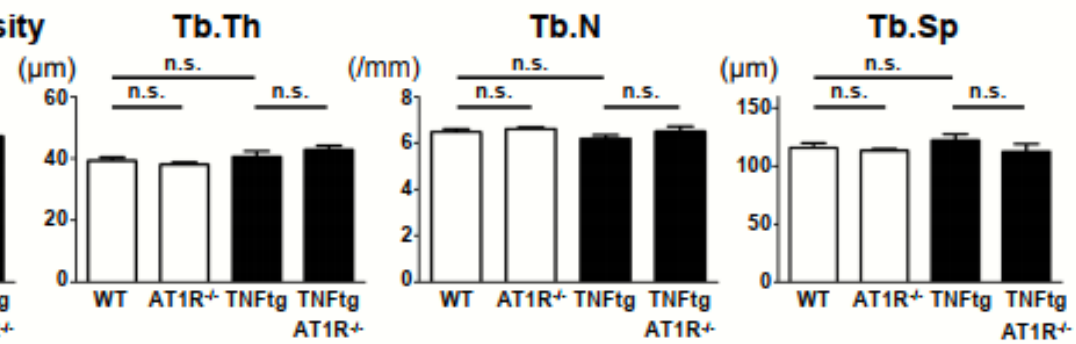

Figure A4. Trabecular and cortical bone parameters of the tibia and spine. Tumor necrosis factor-transgenic (TNFtg) mice were crossed with AT1R-deficient (AT1R ${ }^{-/}$) mice. Wild-type (WT;

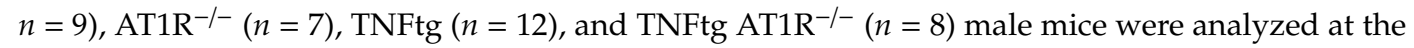
age of 16 weeks. (A) Trabecular bone parameters of the tibia. (B) Cortical bone parameters of the tibia midshaft. (C) Trabecular bone parameters of the spine (fifth lumbar vertebra). Tb.Th, trabecular thickness; Tb.N, trabecular number; Tb.Sp, trabecular separation; Tt.Ar, total cross-sectional area inside the periosteal envelope; Ct.Ar, cortical cross-sectional area. Values are the mean \pm SEM. n.s., not significant. ${ }^{*}, p<0.05$. 

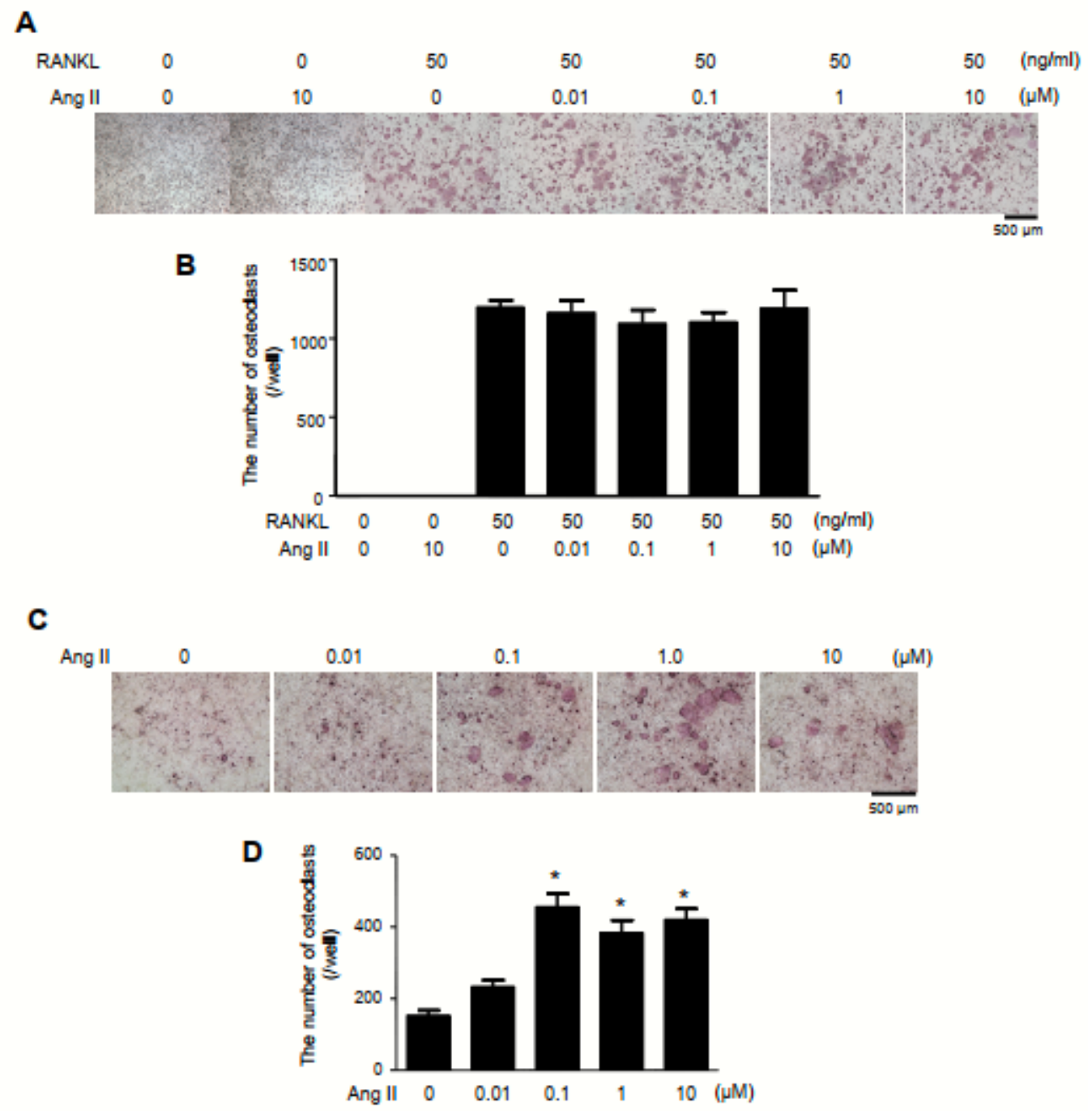

Figure A5. Effect of angiotensin (Ang II) on osteoclast differentiation. Primary mouse bone marrow cells were isolated from the long bones of 10-week-old wild-type mice. Non-adherent bone marrow cells were seeded on 48-well plates and incubated for 2 days with macrophage colony-stimulating factor (M-CSF; $25 \mathrm{ng} / \mathrm{mL}$ ). After pre-culture for 2 days, yielded bone marrow-derived macrophages were stimulated with RANKL $(50 \mathrm{ng} / \mathrm{mL})$ and Ang II at the indicated concentrations for an additional 3 days in the presence of M-CSF. The formation of tartrate-resistant acid phosphatase (TRAP)-positive multinucleated cells (TRAP + MNCs) was visualized by TRAP staining. (A) Representative TRAP staining images. (B) The number of osteoclasts. TRAP + MNCs with three or more nuclei were counted as osteoclasts. Bone marrow-derived macrophages were co-cultured with neonatal calvarial osteoblasts in the presence of $10 \mathrm{nM} 1 \alpha, 25$-dihydroxyvitamin D3, and $1 \mu \mathrm{M}$ prostaglandin E2. The cells were stimulated with Ang II $(0.01-10 \mu \mathrm{M})$ for 7 days. TRAP + MNCs were visualized by TRAP staining. (C) Representative TRAP staining images. (D) The number of osteoclasts. Values are the mean \pm SEM. n.s., not significant. ${ }^{*}, p<0.05$ vs. non-treated control. Detailed methods are described in the Supporting Information.

\section{References}

1. Aletaha, D.; Smolen, J.S. Diagnosis and Management of Rheumatoid Arthritis: A Review. JAMA 2018, 320, 1360-1372. [CrossRef] [PubMed]

2. Smolen, J.S.; Aletaha, D.; Barton, A.; Burmester, G.R.; Emery, P.; Firestein, G.S.; Kavanaugh, A.; McInnes, I.B.; Solomon, D.H.; Strand, V.; et al. Rheumatoid arthritis. Nat. Rev. Dis. Primers 2018, 4, 18001. [CrossRef] [PubMed] 
3. Turesson, C.; O'Fallon, W.M.; Crowson, C.S.; Gabriel, S.E.; Matteson, E.L. Extra-articular disease manifestations in rheumatoid arthritis: Incidence trends and risk factors over 46 years. Ann. Rheum. Dis. 2003, 62, 722-727. [CrossRef] [PubMed]

4. Deal, C. Bone loss in rheumatoid arthritis: Systemic, periarticular, and focal. Curr. Rheumatol. Rep. 2012, 14, 231-237. [CrossRef] [PubMed]

5. Bader, M. Tissue renin-angiotensin-aldosterone systems: Targets for pharmacological therapy. Annu. Rev. Pharm. Toxicol. 2010, 50, 439-465. [CrossRef] [PubMed]

6. Tamargo, J.; Caballero, R.; Delpón, E. The Renin-Angiotensin System and Bone. Clin. Rev. Bone Miner. Metab. 2015, 13, 125-148. [CrossRef]

7. Paul, M.; Poyan Mehr, A.; Kreutz, R. Physiology of local renin-angiotensin systems. Physiol. Rev. 2006, 86, 747-803. [CrossRef] [PubMed]

8. Kagami, S. Involvement of glomerular renin-angiotensin system (RAS) activation in the development and progression of glomerular injury. Clin. Exp. Nephrol. 2012, 16, 214-220. [CrossRef] [PubMed]

9. Zhao, J.; Yang, H.; Chen, B.; Zhang, R. The skeletal renin-angiotensin system: A potential therapeutic target for the treatment of osteoarticular diseases. Int. Immunopharmacol. 2019, 72, 258-263. [CrossRef] [PubMed]

10. Izu, Y.; Mizoguchi, F.; Kawamata, A.; Hayata, T.; Nakamoto, T.; Nakashima, K.; Inagami, T.; Ezura, Y.; Noda, M. Angiotensin II type 2 receptor blockade increases bone mass. J. Biol. Chem. 2009, 284, 4857-4864. [CrossRef] [PubMed]

11. Shimizu, H.; Nakagami, H.; Osako, M.K.; Hanayama, R.; Kunugiza, Y.; Kizawa, T.; Tomita, T.; Yoshikawa, H.; Ogihara, T.; Morishita, R. Angiotensin II accelerates osteoporosis by activating osteoclasts. FASEB J. 2008, 22, 2465-2475. [CrossRef] [PubMed]

12. Gu, S.S.; Zhang, Y.; Li, X.L.; Wu, S.Y.; Diao, T.Y.; Hai, R.; Deng, H.W. Involvement of the skeletal renin-angiotensin system in age-related osteoporosis of ageing mice. Biosci. Biotechnol. Biochem. 2012, 76, 1367-1371. [CrossRef] [PubMed]

13. Yongtao, Z.; Kunzheng, W.; Jingjing, Z.; Hu, S.; Jianqiang, K.; Ruiyu, L.; Chunsheng, W. Glucocorticoids activate the local renin-angiotensin system in bone: Possible mechanism for glucocorticoid-induced osteoporosis. Endocrine 2014, 47, 598-608. [CrossRef] [PubMed]

14. Price, A.; Lockhart, J.C.; Ferrell, W.R.; Gsell, W.; McLean, S.; Sturrock, R.D. Angiotensin II type 1 receptor as a novel therapeutic target in rheumatoid arthritis: In vivo analyses in rodent models of arthritis and ex vivo analyses in human inflammatory synovitis. Arthritis Rheum. 2007, 56, 441-447. [CrossRef] [PubMed]

15. Pattacini, L.; Casali, B.; Boiardi, L.; Pipitone, N.; Albertazzi, L.; Salvarani, C. Angiotensin II protects fibroblast-like synoviocytes from apoptosis via the AT1-NF-kappaB pathway. Rheumatology 2007, 46, 1252-1257. [CrossRef] [PubMed]

16. Kaneko, K.; Ito, M.; Fumoto, T.; Fukuhara, R.; Ishida, J.; Fukamizu, A.; Ikeda, K. Physiological function of the angiotensin AT1a receptor in bone remodeling. J. Bone Min. Res. 2011, 26, 2959-2966. [CrossRef] [PubMed]

17. Asaba, Y.; Ito, M.; Fumoto, T.; Watanabe, K.; Fukuhara, R.; Takeshita, S.; Nimura, Y.; Ishida, J.; Fukamizu, A.; Ikeda, K. Activation of renin-angiotensin system induces osteoporosis independently of hypertension. J. Bone Min. Res. 2009, 24, 241-250. [CrossRef] [PubMed]

18. Brewster, U.C.; Setaro, J.F.; Perazella, M.A. The renin-angiotensin-aldosterone system: Cardiorenal effects and implications for renal and cardiovascular disease states. Am. J. Med. Sci. 2003, 326, 15-24. [CrossRef] [PubMed]

19. Siragy, H.M.; Carey, R.M. Role of the intrarenal renin-angiotensin-aldosterone system in chronic kidney disease. Am. J. Nephrol. 2010, 31, 541-550. [CrossRef] [PubMed]

20. Schett, G.; Gravallese, E. Bone erosion in rheumatoid arthritis: Mechanisms, diagnosis and treatment. Nat. Rev. Rheumatol. 2012, 8, 656-664. [CrossRef] [PubMed]

21. Terenzi, R.; Manetti, M.; Rosa, I.; Romano, E.; Galluccio, F.; Guiducci, S.; Ibba-Manneschi, L.; Matucci-Cerinic, M. Angiotensin II type 2 receptor (AT2R) as a novel modulator of inflammation in rheumatoid arthritis synovium. Sci. Rep. 2017, 7, 13293. [CrossRef] [PubMed]

22. Sakuta, T.; Morita, Y.; Satoh, M.; Fox, D.A.; Kashihara, N. Involvement of the renin-angiotensin system in the development of vascular damage in a rat model of arthritis: Effect of angiotensin receptor blockers. Arthritis Rheum. 2010, 62, 1319-1328. [CrossRef] [PubMed] 
23. Hayward, M.D.; Jones, B.K.; Saparov, A.; Hain, H.S.; Trillat, A.C.; Bunzel, M.M.; Corona, A.; Li-Wang, B.; Strenkowski, B.; Giordano, C.; et al. An extensive phenotypic characterization of the hTNFalpha transgenic mice. BMC Physiol. 2007, 7, 13. [CrossRef] [PubMed]

24. Ito, M.; Oliverio, M.I.; Mannon, P.J.; Best, C.F.; Maeda, N.; Smithies, O.; Coffman, T.M. Regulation of blood pressure by the type 1A angiotensin II receptor gene. Proc. Natl. Acad. Sci. USA 1995, 92, 3521-3525. [CrossRef] [PubMed]

25. Umebayashi, R.; Uchida, H.A.; Kakio, Y.; Subramanian, V.; Daugherty, A.; Wada, J. Cilostazol Attenuates Angiotensin II-Induced Abdominal Aortic Aneurysms but Not Atherosclerosis in Apolipoprotein E-Deficient Mice. Arter. Thromb. Vasc. Biol. 2018, 38, 903-912. [CrossRef] [PubMed]

26. Uchida, H.A.; Sugiyama, H.; Takiue, K.; Kikumoto, Y.; Inoue, T.; Makino, H. Development of angiotensin II-induced abdominal aortic aneurysms is independent of catalase in mice. J. Cardiovasc. Pharm. 2011, 58, 633-638. [CrossRef]

27. Mukai, T.; Gallant, R.; Ishida, S.; Yoshitaka, T.; Kittaka, M.; Nishida, K.; Fox, D.A.; Morita, Y.; Ueki, Y. SH3BP2 gain-of-function mutation exacerbates inflammation and bone loss in a murine collagen-induced arthritis model. PLoS ONE 2014, 9, e105518. [CrossRef] [PubMed]

28. Mukai, T.; Gallant, R.; Ishida, S.; Kittaka, M.; Yoshitaka, T.; Fox, D.A.; Morita, Y.; Nishida, K.; Rottapel, R.; Ueki, Y. Loss of SH3 domain-binding protein 2 function suppresses bone destruction in tumor necrosis factor-driven and collagen-induced arthritis in mice. Arthritis. Rheumatol. 2015, 67, 656-667. [CrossRef] [PubMed]

29. Mukai, T.; Ishida, S.; Ishikawa, R.; Yoshitaka, T.; Kittaka, M.; Gallant, R.; Lin, Y.L.; Rottapel, R.; Brotto, M.; Reichenberger, E.J.; et al. SH3BP2 cherubism mutation potentiates TNF-alpha-induced osteoclastogenesis via NFATc1 and TNF-alpha-mediated inflammatory bone loss. J. Bone Min. Res. 2014, 29, 2618-2635. [CrossRef] [PubMed]

30. Fujita, S.; Mukai, T.; Mito, T.; Kodama, S.; Nagasu, A.; Kittaka, M.; Sone, T.; Ueki, Y.; Morita, Y. Pharmacological inhibition of tankyrase induces bone loss in mice by increasing osteoclastogenesis. Bone 2018, 106, 156-166. [CrossRef]

31. Bouxsein, M.L.; Boyd, S.K.; Christiansen, B.A.; Guldberg, R.E.; Jepsen, K.J.; Muller, R. Guidelines for assessment of bone microstructure in rodents using micro-computed tomography. J. Bone Min. Res. 2010, 25, 1468-1486. [CrossRef] [PubMed]

32. Danks, L.; Komatsu, N.; Guerrini, M.M.; Sawa, S.; Armaka, M.; Kollias, G.; Nakashima, T.; Takayanagi, H. RANKL expressed on synovial fibroblasts is primarily responsible for bone erosions during joint inflammation. Ann. Rheum. Dis. 2016, 75, 1187-1195. [CrossRef] [PubMed]

33. Fujii, Y.; Inoue, H.; Arai, Y.; Shimomura, S.; Nakagawa, S.; Kishida, T.; Tsuchida, S.; Kamada, Y.; Kaihara, K.; Shirai, T.; et al. Treadmill Running in Established Phase Arthritis Inhibits Joint Destruction in Rat Rheumatoid Arthritis Models. Int. J. Mol. Sci. 2019, 20, 5100. [CrossRef] [PubMed]

34. Nagasu, A.; Mukai, T.; Iseki, M.; Kawahara, K.; Tsuji, S.; Nagasu, H.; Ueki, Y.; Ishihara, K.; Kashihara, N.; Morita, Y. Sh3bp2 Gain-Of-Function Mutation Ameliorates Lupus Phenotypes in B6.MRL-Fas(lpr) Mice. Cells 2019, 8, 402. [CrossRef] [PubMed]

(C) 2020 by the authors. Licensee MDPI, Basel, Switzerland. This article is an open access article distributed under the terms and conditions of the Creative Commons Attribution (CC BY) license (http://creativecommons.org/licenses/by/4.0/). 